\title{
Development of the Road Network in the City of Salt in 2004 and 2016 Using GIS
}

\author{
Dr. Deaa Al-Deen Amjad Qtaishat ${ }^{1}$, Dr. Abd Al Azez Hdoush ${ }^{2}$ \& Eng. Loiy Qasim Alzu'Bi ${ }^{3}$ \\ ${ }^{1}$ Faculty member at the Arab University College of Technology, Amman, Jordan \\ ${ }^{2}$ Lecturer, Jordan University, Jordan \\ ${ }^{3}$ Lecturer, Jerash University, Jordan \\ Correspondence: Dr. Deaa Al-Deen Amjad Qtaishat, Faculty member at the Arab University College of \\ Technology, Amman, Jordan. E-mail: Qdeea@yahoo.com
}

Received: August 20, 2019

Accepted: September 18, 2019 Online Published: September 19, 2019

doi:10.5539/mas.v13n10p94

URL: https://doi.org/10.5539/mas.v13n10p94

\begin{abstract}
The aim of this study is to analyze the structure of the road network in As-Salt City in the period between 2004 and 2016, in order to identify the road employability in terms of the degree of connectivity, rotation, accessibility, and density. The relationship between the social properties and road distribution are also examined through analysis of the network characteristics concerning population distribution. The data used in this study was based on the As-Salt City Municipality Database supported with fieldwork done in 2016. The network analysis approach using GIS was used to calculate the roads employability.

The study compares between the results of the analysis using the cognitive model of the road network for the years 2004 and 2016, knowing that the number of nodes in 2004 and 2016 was constant indicating the number of neighborhoods is 20, while the number of links changed from 42 links in 2004 to 50 links in 2016 and the average center of roads was determined, and it was estimated that the average road center is located near the municipality of As-Salt

The study indicates that the road network suffers from a low degree of communication and rotation and the standard distance of road sites in the study area. The standard distance for each group was $2338.49 \mathrm{~m}$. There is a disparity in the distribution of road network within As-Salt City, and the proportion of roads lengths dose not suit the population distribution pattern. The neighborhood of Al- Salalem, includes $19.5 \%$ of the total number of roads in As-Salt, because the neighborhood of Al-Salalem contains the highest population census and this is accompanied by urban growth, which is necessarily accompanied by the presence of roads. Therefore, it is recommended to have a plan to redistribute the population in the city and to establish new roads to reduce the problems of traffic in the city.
\end{abstract}

Keywords: rotation, road network, GIS, Jordan

\section{Introduction}

Residents benefit from a good transport system because they have easy access to their destinations and to all areas of the city they want to reach. People can easily navigate shopping, entertainment and visits, moving from residential areas to workplaces to shorten distances and time to move. Allocation of high percentages of investment development plans for the transport sector. The transport sector plays an important role in the planning process in general, because it facilitates movement from one place to the other. The quality of roads should be taken into account and congestion areas that obstruct traffic should be taken into consideration. (Al-Tarazi, 2003)

Transportation is one of the most important human activities that is closely related to the place. It is reflected in different ways in our lifestyle. Also, human movements are composed of mutual relation between the road network as a place and humans as a user (Nawayseh, 2016).

Road network is part of the transportation system which stimulates traffic demand because it is considered as a type of land use (Asadi, 2016), on the other hand, it plays a role in the distribution of land use (Tongfei, 2015), which is confirmed by (Zhong, 2016). Road network is one of the infrastructure services which is an increasing 
interest to the local municipality because it is important in the development and sustainability of the economic and social quality of life (Shabat, 2011).

Transportation had received an enormous development in the world during the last century, and Jordan was not far from this development. Since the founding of the Jordanian state in 1921, this sector has been given a lot of attention to developing the transport system. Accordingly, a new department was established called the "Ministry of Public Works and Housing" which took it upon themselves to set up a sophisticated network of roads connecting the parts of the Kingdom to each other (Siam, 1993). In 1988, the housing department and the ministry of public works were linked together and became the ministry of public works and housing, in 2001 the Public Transport Authority was established. Sincethe development of the Transport sector, a lot of problems have been arising due to high population growth, poor planning of cities, and lack of a cohesive transport system.

This situation has been reflected also on As-Salt City in Al-Balqa district. The urban expansion, high population growth, and mountains nature of the city has worsened the problem, and therefore, there was a need to expand the city boundaries many times by the Municipality to solve the transport problems. Accordingly, new administrative boundaries were added to the municipalities such as Al- Saru, Um Zaitona, Batna, and Kafur Hudo. The recent indications show that the AsSalt city is suffering from high traffic density and weakness of road networks, also there is a weakness in transportation links between the city center and the city intersections.

Therefore, traffic problems became a serious issue in the city, which affect directly the viability of the transportation system and increase the costs of transport for goods and people. The objective of this study is to analyze the structure of the road network in As-Salt City, in order to identify the reality of the road network in terms of the degree of connectivity, rotation, accessibility, density, and topography.

\section{Literature Review}

Alloush (2012) discussed the main causes of accidents and traffic jams, and found solutions in order to reduce accidents and their social effects. The study showed the pattern of roads, accidents and weather conditions in the city of Hilla in three main axes. It presented many suggestions, the most important was to establish asset of modern methods and specifications to serve the increasing number of cars and to maintain the old roads and repair the damages frequently to avoid huge damages caused by a long period.

Al-Jabere (2010) explained the transportation as a geographic issue which is one of the branches of economic geography. It aims to study the current situation of transportation in Jenin governorate in terms of roads, traffic volume and the factors affecting it, and to find solutions for the traffic problems. The most important result was the increasing value of the road turning point because of the nature and topography of the area, and it discussed the effect of the barrier on roads and traffic. The most important recommendations were encouraging people to use public transportation in order to reduce environmental impact and traffic jam, especially during peak hours.

Taran (2015) study the spatial analysis of the road network in Mafraq government using GIS in analyzing the road network. Specifying the network functionality in linking the center of the government on one hand and its urban and service centers on the other. The study evaluates the efficiency of the road network in the governorate by measuring its distribution and continuity. It found that the road network characterized by a low degree of continuity links where the rate of the relation is less than $42 \%$, and the alpha index didn't exceed $11 \%$.

Al-Masri (2009) Analyzed the road network in Damascus, its service efficiency and productivity to determine the impact of geographical factors in the development and the extension of the road network using the historical, descriptive, statically and cartographic approaches. Many study and analyze natural, human and economic factors affecting the extension of the road network, the climate is the most important impact factors did not impact mainly on the work of transportation in Damascus. The urban structure in old Damascus and in random neighborhoods prevented the extension of the road network and the use of modern transportation. Most of traffic jam cases occurred at the intersections, several recommendations were reached such as making traffic in the main road permanently functional by establishing two levels of traffic at some intersections which allow the continuity of traffic and reduction of traffic jams. The periodic maintenance of pedestrian sidewalk resolve some problems related to it.

Sarker (2013) study the composition of the network in the Kuchbihar city, which is located west of Bengal in India. The objective of the study is to provide an overview of the current road network and to determine the status and spatial variation of roads network development. The study area suffers from low efficiency of the road network which effects the movement of people and goods.

Xie and Yetal (2016) analyze the spatial and temporal changes in the city within the major road intersections to compare the relationship between city growth in arid regions in China. The results showed that the main roads 
encouraged the expansion of the city especially for the construction of green land areas. The methodology of the study captures images and process them using software's, by collecting sufficient samples and correcting them in geographical scales, then testing them through surveys including ground control points using GPS and comparing them with the original images.

Zhao and Fetal (2016) proposed a new road network model which depends on the distribution of population and the attractiveness of Beijing, China. He represented a new method to provide topographic characterization which simulates the distribution and the gravity of the work in the road network. The proposed model has been verified to simulate the high-speed road networks. The study concluded that the effect of population distribution and topographic work of the road was taken into account simultaneously.

Jeong et al, (2016) linked a small and medium-sized city with a low class socially and economically. Despite the high attention and studies focused on the global network of major cities few of these test the local impact of travelers, shipment and migration flow on the formation of a city network especially the cities in a low order and less fortunate. The study found that it may be difficult to develop a new transport network in small cities. City planners should consider the separation of existing transport links and balance between resources and services to promote sustainable development in the region which achieves well economic growth.

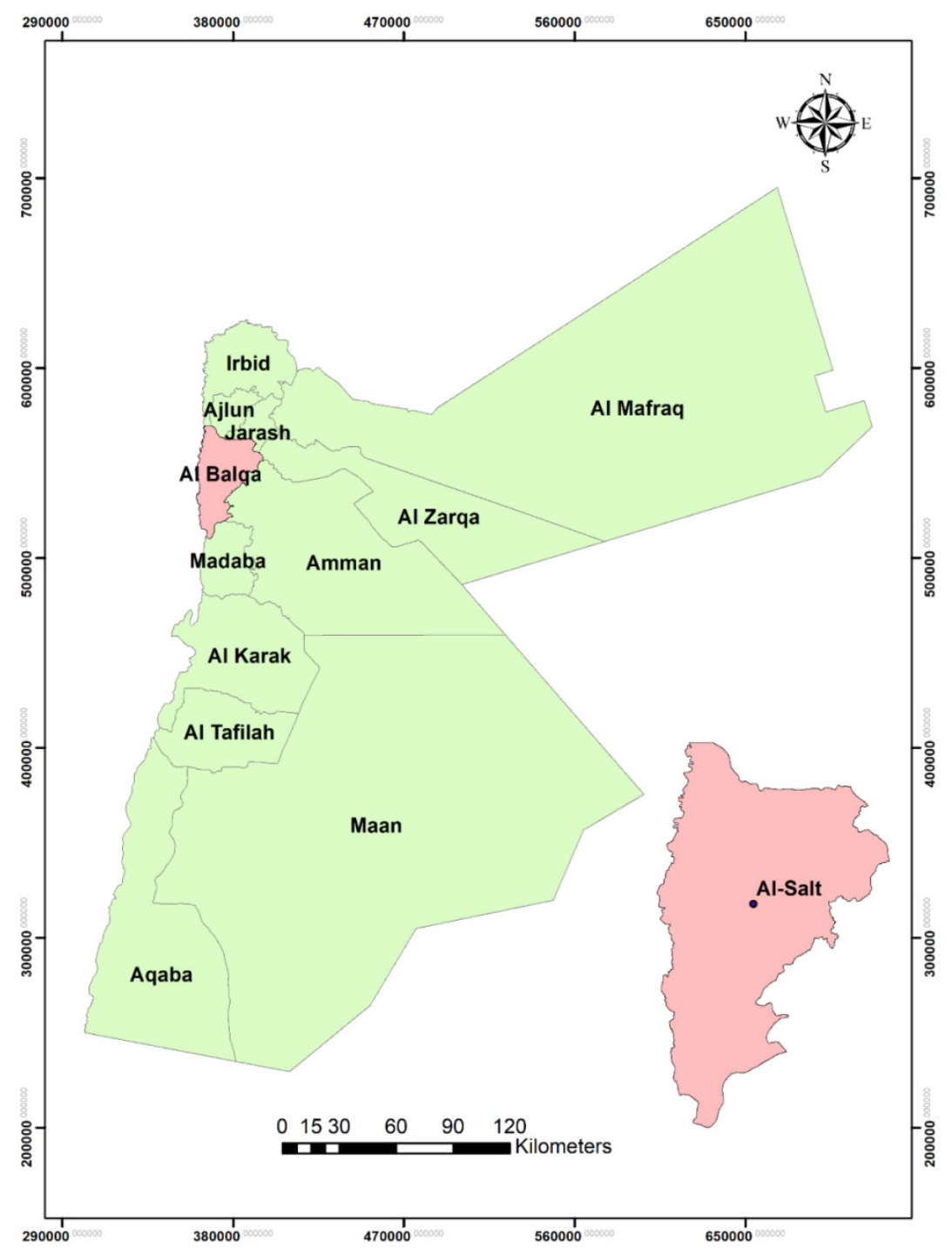

Figure 1 . The study area 


\section{Study Area}

As-Salt City is the administrative center of the Al-Balqa governorate which is situated on the west heights, about $900 \mathrm{~m}$ above sea level. It is located about $28 \mathrm{~km}$ northwest of Amman City, the capital of Jordan. The geographical location of the city is (754000) East and (3552000) North as shown in Figure (1).

The total area of the city is $48 \mathrm{~km}^{2}$ which represent $4 \%$ of the area of Al-Balqa governorate. The population of As-Salt is 99938 thousand inhabitants for the year 2014 which makes about $21.2 \%$ of the population of Al-Balqa governorates (447200) inhabitants. The prevailing climate of the city is the Mediterranean, and is characterized by a rainy season from late October to the end of April, and the summer is characterized as dry and hot starting from late May to the end of September. Landscape surfaces and terrain features vary from open plains and flat lands to hills that are moderate to hilly steep, while the mountains area contains steep and downhill valleys and very steep canyons. The soil type is considered one of the most fertile in Jordan which support various agricultural land use types (Greater Al Salt Municipality, 2016).

\section{Methodology}

The study was based on the analytical approach to identify the general characteristics of the road network in As-Salt City such as length, width, classification development, and the geographical distribution of the network. The data source was based on electronic and paper resources maps from the greater Salt municipality and street layers from the Jordanian Ministry of Works. This allows for using the spatial analysis tools and the network analysis module. The spatial and network analysis was carried out using geographic information systems. It applies the neighborhood feature which varies between $0-2.15$ for each value and has a significant mean indicating a spatial distribution, if the value equals to zero; it means concentration point, if the value equals to 2.15 it means spread and big spacing as shown in table 1 .

Table 1. shows the value of neighborhood link

$\begin{array}{cc}\text { Distribution pattern } & \text { Quantitative significance of } \\ \text { neighborhood } \\ \text { link }\end{array}$

\begin{tabular}{|c|c|c|c|}
\hline$\because$ & & Assembled in one place & $\mathrm{R}=0$ \\
\hline$\because \because \because$ & & $\begin{array}{l}\text { The closer it is to zero they were gathered } \\
\text { The closer it is to } 0.5 \text { the pattern is close - } \\
\text { The closer it is to one the pattern the more random - }\end{array}$ & $1>\mathrm{R}>0$ \\
\hline$\because \because \because$ & $\begin{array}{l}\text { Random } \\
\mathrm{R}=1\end{array}$ & $\begin{array}{l}\text { The random pattern is also considered harmonic because the actual distance is close } \\
\text { to the theory }\end{array}$ & $\mathrm{R}=1$ \\
\hline $\begin{array}{llll}\bullet & \bullet & \\
& \bullet & \bullet & \bullet \\
\bullet & \bullet & \bullet \\
\bullet & \bullet & \bullet \\
& \bullet & \bullet \\
\bullet & \bullet & \bullet \\
\end{array}$ & $\underset{\substack{\mathrm{R}=2.15 \\
\text { Dispersed }}}{\downarrow}$ & $\begin{array}{l}\text { The closer the one was to the style, the closer to random. The closer the value of } 2.1 \\
\text { the pattern was (regular) }\end{array}$ & $2.15>R>1$ \\
\hline
\end{tabular}

The neighborhood link method of the road network was measured by measuring the real distance between the geographical location of each station and the geographical location of the nearest station, then the average distance between all stations was calculated. The neighborhood correlation coefficient is calculated by applying the mathematical formula. This allows calculating the distance between all stations, by divide the calculated rate on the expected rate of the total distances between stations as given in equation (1)

$$
R=2 D x\left(\frac{N}{A}\right)^{2}
$$

Where:

$\mathrm{R}=$ Value of the neighborhood link 
$\mathrm{D}=$ Real distance between the road network stations

$\mathrm{N}=$ Number of the road network stations

$\mathrm{A}=$ Area of the study area

In addition to analyzing the reality of transportation network using the statistical method in terms of number of cars, population and spatial analysis of the road network the study use to apply the following formula (2) (Hurst, 1974)

$$
\mathrm{e}=\mathrm{v}-1
$$

Equation (2)

where:

$\mathrm{e}=$ Number of roads or lines

$\mathrm{v}=$ Number of stations or points

The complex network consists of a large number of alternative roads such as double and circular roads which provides continuity between stations in the network. The study area is an example of this type of network which has an advantage; if one of these roads closed for any reason it doesn't affect the other stations in the network.

The study used the beta index which depends on two basic criteria: the number of lines and the number of points. The value of this index ranges between (0-1). The zero value indicates that there is only one set of points and there are no road lines, while the value of one expresses the full network connection if the value exceeds one this means that there is more than one integrated road network at the same time, the beta index is determined by equation (3).

$$
\beta=\mathrm{e} / \mathrm{v}
$$

Where:

$\beta=$ beta index

$\mathrm{e}=$ Number of roads or lines

$\mathrm{v}=$ Number of station or points

The study also uses the gamma index which measures the relationship between the number of lines and roads in the real network and the maximum number of lines that can be set up in this network. The value of this scale ranges from (0-1), the zero means no interconnection.

The study is based on measuring rotation index which is one of the most important factors in the evaluation of the transportation networks. It shows the progress and development in this network, thus reflects in the improvement of services. The rotation means that there is a close road which means the starting point will be finishedtoo.

The alpha index is also used in this study which represents the relationship between the number of circular roads in the current network and the maximum number that can be set in this network, the alpha index value ranges between $(0-1)$.

Finally, the study measures the extent of the deviation of the real road length in a straight line - shortest distance - which is called the turning index, there are two types of it: - these are the positive and the negative turning indices.

\subsection{Spatial Statistical Analysis}

The spatial analysis facilities available in the geographic information system was used to analyze the land use distribution and road network characteristics. The aerial photo and satellite images and land have been used to map and analyze the existing land use types using on-line digitizing methods with high accuracy. GIS spatial models have been used to predict the future urban development direction of the city, and its effect on the transportation network and population growth. The classification scheme was based on the Administration of Urban Renewal and the Office of Public Roads, this scheme based on the following characteristics: the building, the total floors' size for buildings and the size of the ground floor.

The statistical analysis of the road network was based on the following steps:

\subsubsection{The Density of the Roads Network in Relation to the City Size}

The density of the roads network in relation to the size is equal to the total summation of the roads network length to the city size multiplied by 100 as given in equation (4). 
$\mathrm{D}=\left(\sum \mathrm{L} / \mathrm{S}\right) * 100 \%$

Equation (4)

$\mathrm{D}=$ Density of the roads network

$\sum \mathrm{L}=$ Summation of the total roads' length

$\mathrm{S}=$ Area of the city

4.1.2 Measuring the Density of the Roads Network in Relation to Population Size

Measuring the density of the roads network in relation to population is considered the best measurement method, population is the most important variable and influence to the viability of the roads network, and provide the accessibility for the economic activity.

The density of the roads network is equal the summation of roads' length in relation to the population multiplied by 10 thousand as given in equation (5).

$$
\mathrm{D}=\left(\sum \mathrm{L} / \mathrm{P}\right) * 10000
$$

Equation (5)

$$
\begin{aligned}
& \mathrm{D}=\text { The density of the roads network } \\
& \sum \mathrm{L}=\text { Summation of the total roads' length } \\
& \mathrm{P}=\text { Population number }
\end{aligned}
$$

\subsubsection{The Density of Roads in Relation to the Vehicles Count}

The density of roads based on vehicles count is the sum of roads' length to the number of cars multiplied by a thousand as given in equation (6)

$$
\mathrm{D}=\left(\sum \mathrm{L} / \mathrm{V}\right) * 1000
$$

Equation (6)

$\mathrm{D}=$ Density of the roads network to vehicles number

$\sum \mathrm{L}=$ Summation of roads lengths

$\mathrm{V}=$ Number of vehicles

4.1.4 The Mean of People Number Per Vehicle can be Calculated Using Equation (7)

$$
\mathrm{M}=\mathrm{P} / \mathrm{VN}
$$

Equation (7)

$$
\begin{aligned}
\mathrm{M} & =\text { Mean of people number per vehicle } \\
\mathrm{P} & =\text { Population } \\
\mathrm{VN} & =\text { Vehicle number }
\end{aligned}
$$

\section{Result and Discussion}

\subsection{Road Lengths in Salt City}

Studying lengths of roads is important when dealing with the analysis of the spatial relations of road networks. It provides a detailed explanation of the reality of this network and its role in developing the cities. As-Salt City constitute $4 \%$ of the road of the kingdom of Jordan as shown in figure (2). 


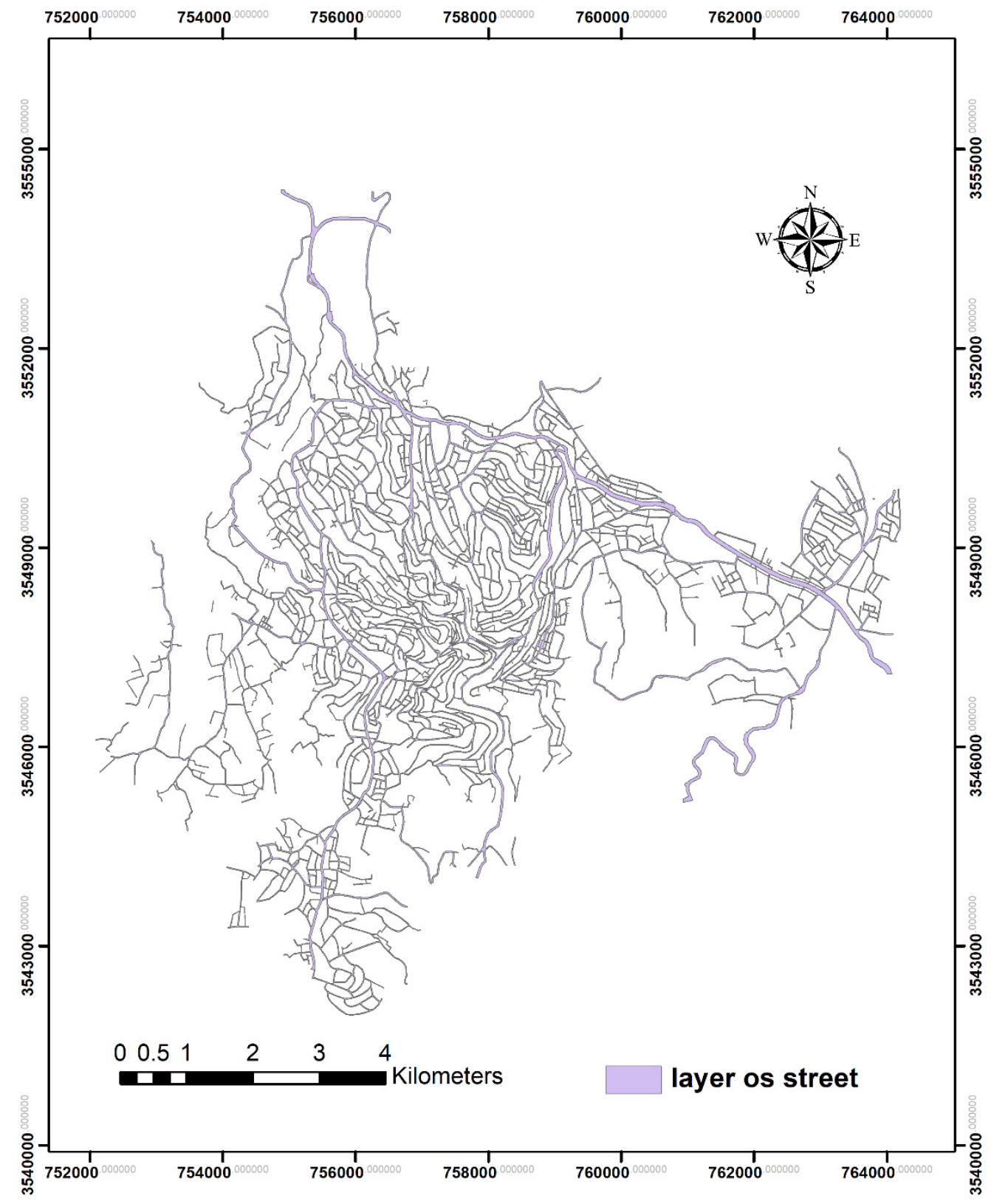

Figure 2. Represents the streets in study area

Table 2 Shows the lengths of roads distributed in the neighborhoods of the city of As-Salt 
Table 2. The length and types of roads network in Al Salt city

\begin{tabular}{ccccc}
\hline $\begin{array}{c}\text { The name of the } \\
\text { neighborhood }\end{array}$ & $\begin{array}{c}\text { Lengths of } \\
\text { roads }\end{array}$ & $\begin{array}{c}\text { Ratio } \\
\%\end{array}$ & $\begin{array}{c}\text { Lengths of } \\
\text { roads }\end{array}$ & $\begin{array}{c}\text { Ratio } \\
\%\end{array}$ \\
\hline Kalaa & 2004 & & 2016 & \\
Wade-halbee & 9.72 & 1.5 & 9.73 & 1.16 \\
Al-Medan & 18.52 & 2.98 & 8.12 & 0.97 \\
Al-Jadaa & 3.29 & 0.52 & 3.29 & 0.39 \\
Al-Mansheeh & 5.11 & 0.82 & 5.11 & 0.61 \\
AL-Aezreah & 10.89 & 1.7 & 10.89 & 1.3 \\
Wadi Krad & 8.08 & 1.3 & 8.09 & 0.96 \\
Al-Safeh and Baqeea & 14.63 & 2.35 & 14.63 & 1.74 \\
Sawaada & 94.75 & 15.2 & 112.05 & 13.3 \\
Kfarhuda & 76.49 & 12 & 76.56 & 9.15 \\
Al-Msalaa & 22.79 & 3.67 & 61.62 & 7.36 \\
Al-Salalem & 8.03 & 1.2 & 18.76 & 2.24 \\
Alnaqeb & 121.37 & 19.5 & 121.42 & 14.51 \\
Alshafaa & 40.64 & 6.5 & 40.66 & 4.86 \\
Al-Serwo & 58.65 & 9.4 & 60.46 & 7.22 \\
Batnaa & 40.63 & 5.81 & 89.14 & 10.65 \\
Al-Qassam & 35.35 & 5.69 & 57.27 & 6.84 \\
Aom Zitone & 18.22 & 2.9 & 23.6 & 2.82 \\
Al-Miamen & 3.9 & 0.62 & 16.9 & 2.02 \\
Al-Mzawad & 8.7 & 1.4 & 57.37 & 6.85 \\
Total & 25.67 & 4.1 & 40.63 & 4.85 \\
& 620.9 & 100 & 836.3 & 100 \\
\hline
\end{tabular}

Table 2 shows that the neighborhood of Al-Salalem forms $19.5 \%$ of the total roads of the city, because the neighborhood of Al-Salalem contains the largest population census and this is accompanied with urban growth, which is necessarily accompanied by the presence of roads Figure (3) shows the boundaries of Al-Salalem 


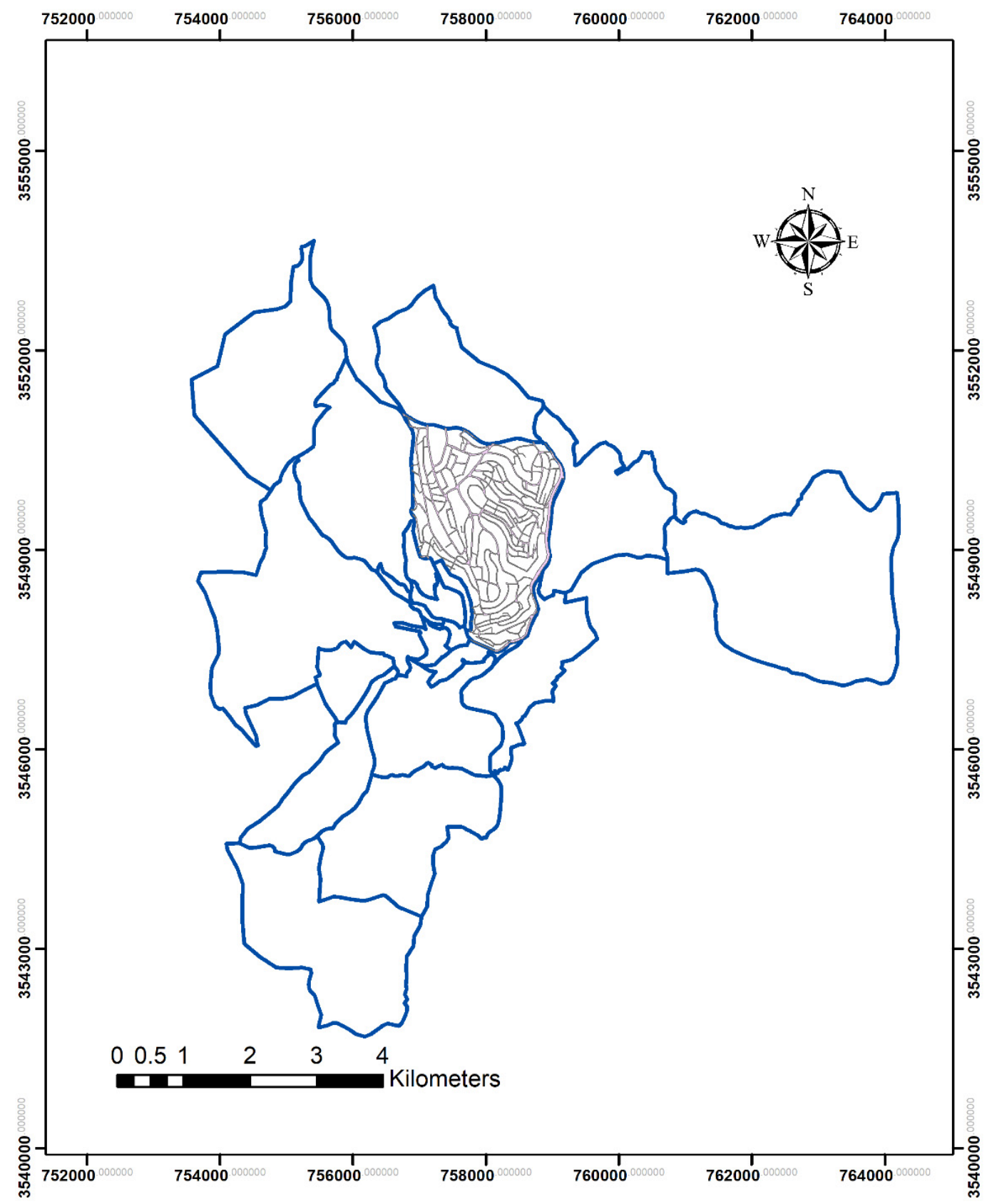

Figure 3. Distribution of roads in the neighborhood of Al-Salalem

Table 2 shows that Al-Midan district has the lowest ratio of roads by $0.52 \%$ of all roads in the city in 2004 and the percentage of roads in Al-Midan district in 2016 reached $0.39 \%$ of the total roads of Salt, and Figure (4) represents the road distribution in Al-Midan district. 


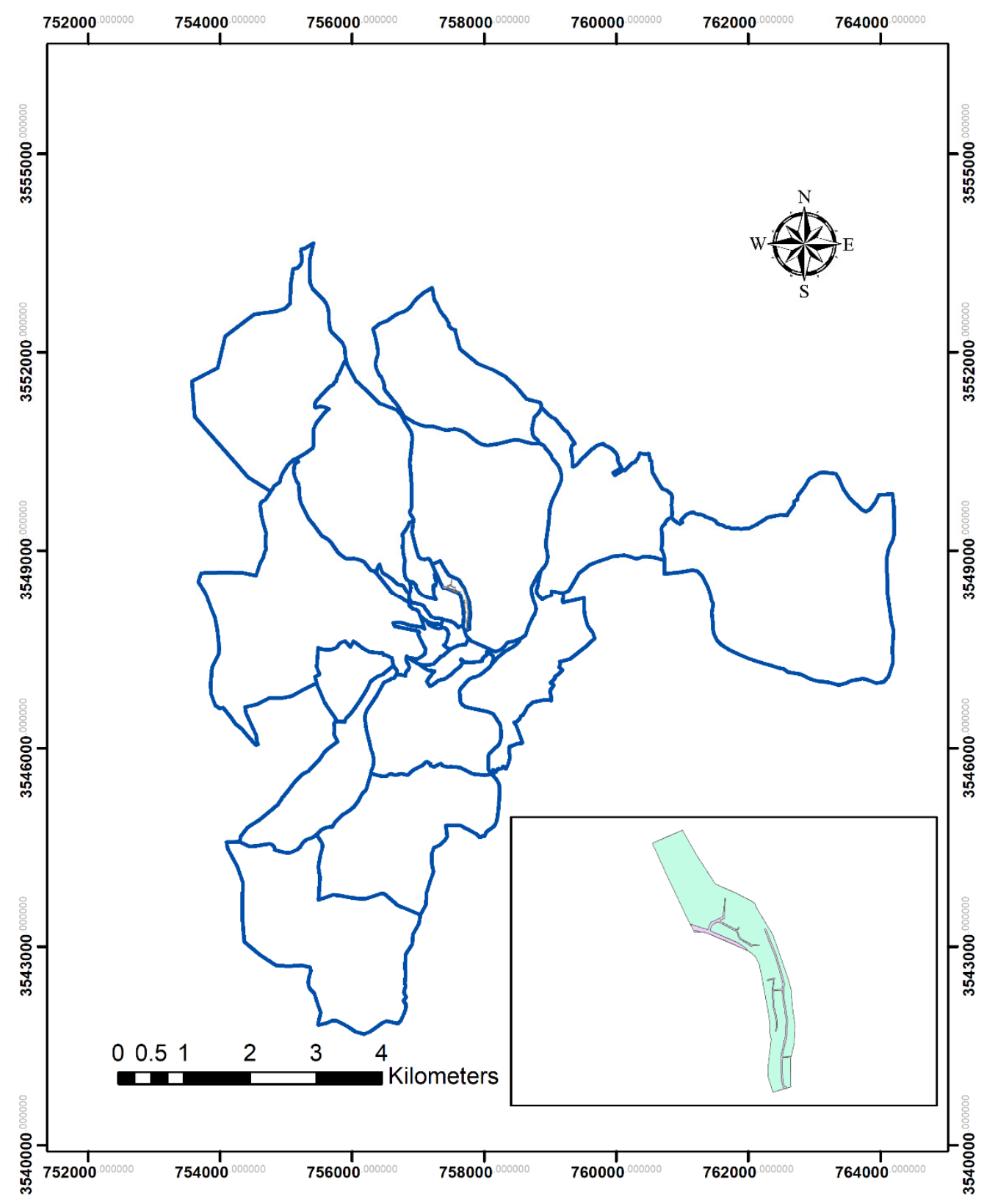

Figure 4. Distribution of roads in the neighborhood of Al-Midan

\subsection{The Distribution Pattern of Nodes in the Transportation Network}

The nearest neighborhood method is one of the most important measurements for geographers because it provides an accurate measurement. This measure is based on a continuous quantitative criterion to determine the spatial distribution of the road network (Abu al- Nasr, 2012). Applying the neighborhood link test on the road network stations in As-Salt City shows the dispread pattern which founds that the average distance between two nodes was 79.8922 , this means it was more than the expected value 63.4932. This pattern indicates that the separation and regularity in the distribution of the population as shown in figure (5). 


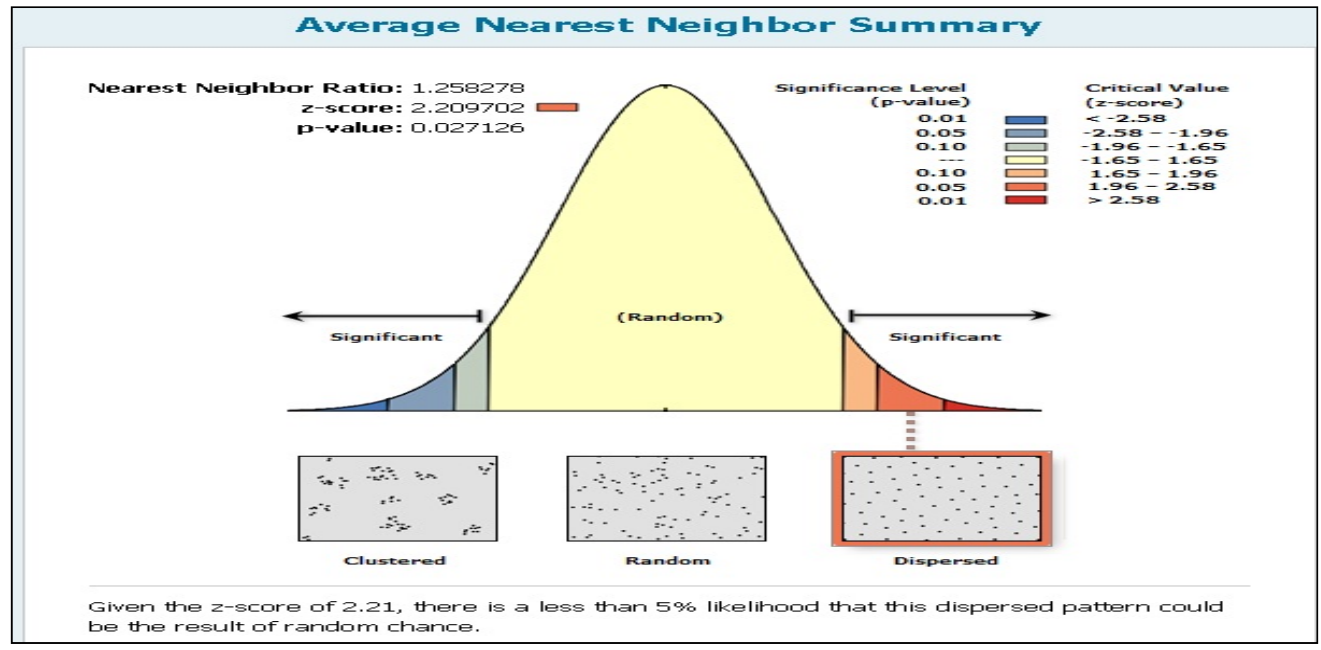

\begin{tabular}{|r|l|}
\hline \multicolumn{2}{|c|}{ Average Nearest Neighbor Sum mary } \\
\hline Observed Mean Distance: & 79.892167 \\
\hline Expected Mean Distance: & 63.493241 \\
\hline Nearest Neighbor Ratio: & 1.258278 \\
\hline z-score: & 2.209702 \\
\hline p-value: & 0.027126 \\
\hline Da taset Information \\
\hline Input Feature Class: & Nods \\
\hline Distance Method: & EUCLIDEAN \\
Study Area: & 322511.332421 \\
\hline
\end{tabular}

Figure 5. The output of the nearest neighbor average

Table 2 shows that after the application of the neighborhood link test on the road network stations in As-Salt City in 2004, the prevalence of the pattern was the usual spread (the actual mean distance between the contract (79.8922) for the year 2004 was more than the average expected distance of 63.4932), resulting in the recording of the nearest neighbor value of (1.25828). This pattern indicates the separation and regularity in the distribution of the population (the contract) in the study area. In 2016, the actual average distance between the contract (419.04) was more than the average expected distance of (173.7), resulting in the nearest neighbor recording a value of (2.3706) and this shows the pattern of spacing and regularity in the distribution of population centers (nodes) in the study area for the year 2016.

Table 3. Apply the neighborhood link to both periods of the study

\begin{tabular}{ccc}
\hline & $\mathbf{2 0 0 4}$ & $\mathbf{2 0 1 6}$ \\
\hline Mean distance & 79.89 & 419.04 \\
Average expected distance & 63.49 & 173.7 \\
Nearest neighbor ratio & 1.25 & 2.37 \\
\hline
\end{tabular}

\subsection{Graph Models for the Study Area}

Drawing the graphs for the real network facilitates the analysis of the complex network structure by identifying its topological characteristics to measure the degree of connectivity and its ability to rotate. It can be said that when the network is represented graphically we can determine the number of nodes easily. These graphical models did not deal with the economic and engineering characteristics of the network such as the capacity of the road, lane width, traffic volume, and the type of material used in construction, in other words, this method focuses on the number of lines and nodes (Tamimi, 1991) 


\subsection{The Degree of Interconnection of the Road Network in the Study Area}

Knowing the degree of connectivity of any region is very important in terms of planning. When determining the connectivity of the city in the road network, the traffic indicators can be identified such as the volume, accessibility, and movement on this network which is important to guide urban management. There are many types of road networks depending on their degree of connectivity such as simple network which achieves minimal connectivity, it consists of a few road links between residential places. There is only one road between two stations so that any road network interruption will result in separating the network into two parts. These networks are usually located in mountainous areas with difficult topography and steep slopes because of the difficulty in opening alternative roads as well as the high economic cost of road construction due to steep terrain. This type of networks has a number of roads less than the number of stations by one, so it is easy to know the number of ways it connects with stations in the network.

\subsection{Beta Index}

This index indicates that the value of node which connects links is 2.1 lines, and since this index exceeds 1 this means there is more than one road leading to the same place. For example, Musala, Kafur Huda, Ezarya, Safeh, and Boaqi are connected with 4 lines which means there are 4 roads to reach the center. Furthermore, it found that most of the road networks are connected by three lines or more, this indicates that the road network connection in As-Salt City is good.

\subsection{Gamma Index}

This index measures the relationship between the actual number of lines (roads) in the real network and the maximum number of lines that can be set up in this network. The value of this index varies between $(0-1)$, zero means no connection. When the gamma index reaches to 1 it means full network connectivity and completeness. The equation (9) below is used to find $\gamma$ index

$$
\gamma=\mathrm{e} / 3(\mathrm{v}-2)
$$

Equation (9)

Where:

$\gamma=$ Gamma index

$\mathrm{V}=$ Number of stations

$\mathrm{e}=$ Number of roads or lines in the area

By applying this formula to the road network in As-Salt City, the value of gamma is equal to 0.77 . This value can be converted to percentages $77 \%$, it means that the network is well interconnected, to integrate this network we need to add new lines to the network to increase connectivity.

\subsection{Rotational Network of Roads.}

The rotational index is an important factor to assess the transportation network. It shows the progress and development of this network and how it reflects in the country. Rotation means a closed road such as the (60th street) in As-Salt, where there are many lines to reach the station. The number of circular roads can be calculated in the complex road network using the following mathematical formal (10) (Hurst, 1974)

$$
\mathrm{C}=\mathrm{e}-\mathrm{v}+1
$$

Equation (10)

Where:

$\mathrm{C}=$ Number of rotations in the network

$\mathrm{e}=$ Number of lines

$v=$ Number of stations or nodes

By applying the pervious formula, the value of rotational number indicates that the number of circular roads in the road network in study area reached 23 circular roads.

\subsection{Alpha Index}

This index can be calculated using equation (11)

$$
\alpha=\mathrm{e}-\mathrm{v}+1 / 2 \mathrm{v}-5
$$

Where:

$$
\begin{aligned}
& \alpha=\text { Alpha index } \\
& e=\text { Number of lines (road) }
\end{aligned}
$$


$\mathrm{v}=$ Number of stations

$(\mathrm{e}-\mathrm{v}+1)$ provides the number of circular roads in the current network

$(2 \mathrm{v}-5)$ provides the maximum number of circular roads that can be set up the in the network

The alpha index can be expressed in percentage by multiplying the index by 100 . By applying this formula on the road network in As-Salt the index returns the value of $\alpha=0.65$ which means that $65 \%$ of the network roads are circular. The alpha index indicates the possibility to increase the number of lines in the current network to produce circular road connectivity between existing centers, as to increases the efficiency of the network and reduce traffic jam.

\subsection{Turning Index}

This index is the ratio between the length of the real road and the shortest possible length for the same road, it can be represented by the following equation (12)

Turning index $=$ length of red road / shortest length of road *100

Equation (12)

When the turning index value reaches $100 \%$ that means the road is closest to being straight and provides more efficiency, however when the value is farther away from $100 \%$ that means the road is more inflected and less efficient. It is rare that the real road distance and the shortest distance would be equal. Knowing that the turning index reduces time and shortens the distances, in addition, to reducing the costs of road constructions as shown in Table (4) and Figure 5.

Table 4 shows a comparison between the results of the analysis using the cognitive model of the road network for the years 2004 and 2016, knowing that the number of nodes in 2004 and 2016 were constant indicating the number of neighborhoods as 20, while the number of links changed from 42 links in 2004 to 50 links in 2016.

Table 4. Comparison between the analysis of the cognitive model using the index for the two periods of study

\begin{tabular}{ccc}
\hline Type of relationship & $\mathbf{2 0 0 4}$ & $\mathbf{2 0 1 6}$ \\
\hline Beta index & 2.1 & 2.5 \\
Gamma index & 0.77 & 0.92 \\
Turning index & 23 & 31 \\
Alpha index & 0.65 & 0.88 \\
\hline
\end{tabular}




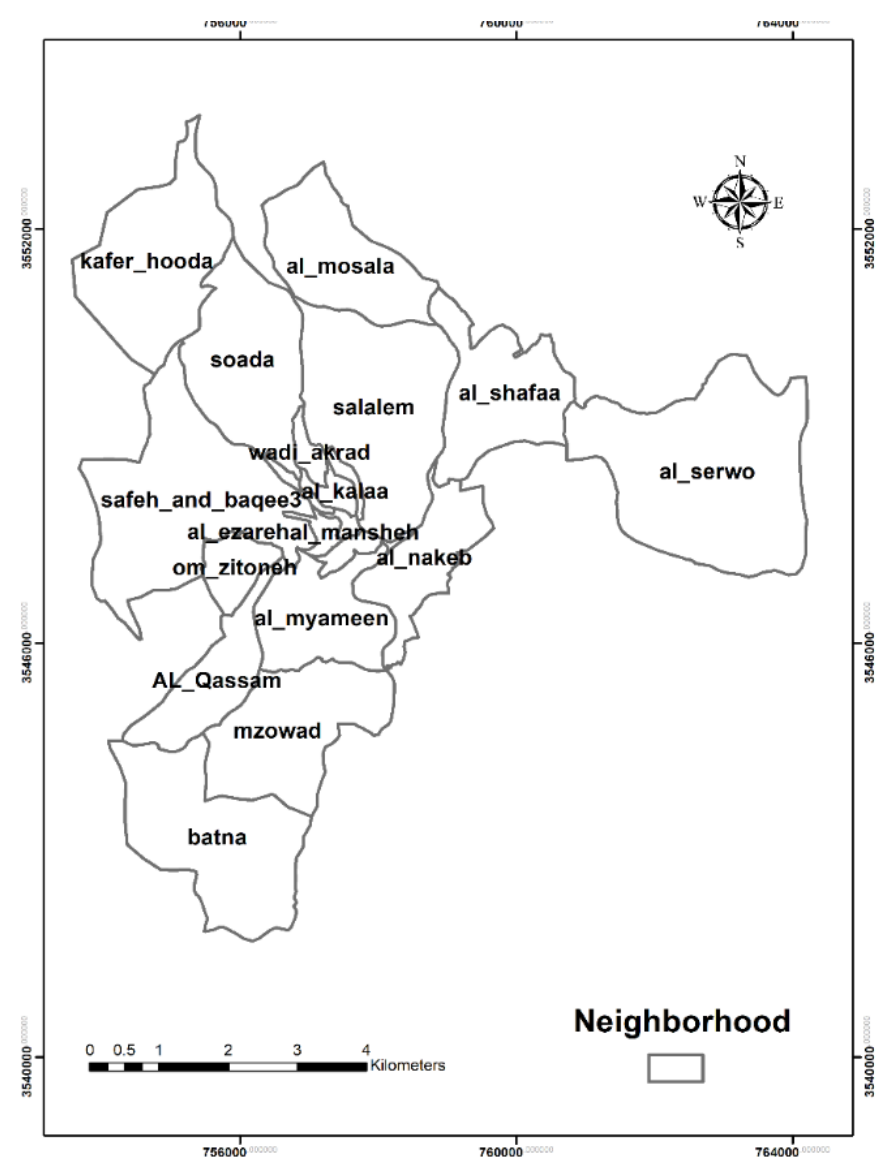

Figure 5. Neighborhood regions in the As-Salt City

\subsection{Road Network Density}

The development strategy of the city is based on the road network density index, total length, and good performance. It is a quantitative method to evaluate the services provided by roads.

\subsubsection{Road Network Density Based on Area}

There is a relationship between the completion of infrastructure and the density of roads in the city of As-Salt. The measurement of road density expressed as a ratio between the length of the paved roads to the area of the road or population. Road network density indicates the rate of completion of infrastructure, which means the network in the city needs more intensive development (Abu-Madina, 2008) by applying the equations (8) on the road network:

Road network density based on area $=$ total road length / area of Salt city $* 100$

$=620 \mathrm{~km} / 48 \mathrm{~km}^{2} * 100$

$=1293.5 \mathrm{~km}$

\subsubsection{Road Network Density Based on Population}

The density of the road network for a population is the best measure because the population is one of the most important variables that affect road network and economic.

Road network density based on population $=$ total road length in $(\mathrm{km}) /$ no. of population *10000

By applying this equation in As-Salt City

$(620.9 \mathrm{~km} / 94749) * 10000=65.5 \mathrm{~km} / 10000$ inhabitant

5.10.3 Road Network Density Based on the Number of Vehicles

It is defined as the ratio of the total length of road lines to the number of vehicles, multiplied by 1000 (Tarazi, 2003). 
Road network density based on no. of vehicle $=$ total length of road $/$ no. of vehicle $* 1000$

By applying this equation in As-Salt City

$(620.9 \mathrm{~km} / 38469$ Vehicles $) * 1000=16.1 \mathrm{~km} / 1000$ vehicles.

Table (5) shows that the low density of the roads in the city is due to the large increase in the population and therefore the increase in the number of vehicles at the expense of the density of the road network. It was found that the density of roads for the population is very close to each other because the increase in population accompanied by an increase

Table 5. Comparison of road network density in the city of As-Salt for the years (2004 - 2016)

\begin{tabular}{ccc}
\hline Variable name & $\mathbf{2 0 0 4}$ & $\mathbf{2 0 1 6}$ \\
\hline Number of vehicles & 13755 & 38469 \\
Road density for area & 12.93 & 17.42 \\
Density of roads for the & 84.44 & 83.7 \\
population & & 21.7 \\
Road density for vehicles & 45.1 & 2.5 \\
Average number of personnel & 5.3 & \\
per vehicle & & 2004 \\
\hline
\end{tabular}

Table (5) shows that the density of roads in relation to vehicles decreased in 2016 because most of the population tended to use vehicles rather than public transportation, and also the increase of population led to an increase in the number of vehicles.

\subsection{Analysis of the Center of the Average or Geographic Center}

This means that the center of the roads in a spatial distribution, defines the teacher or the geographical phenomenon that mediates all the lines of the study area. Using this method, the average center of roads was determined, and it was estimated that the average road center is located near the municipality of As-Salt, Figure (6) shows the Central Feature in the roads of the city of As-Salt. 


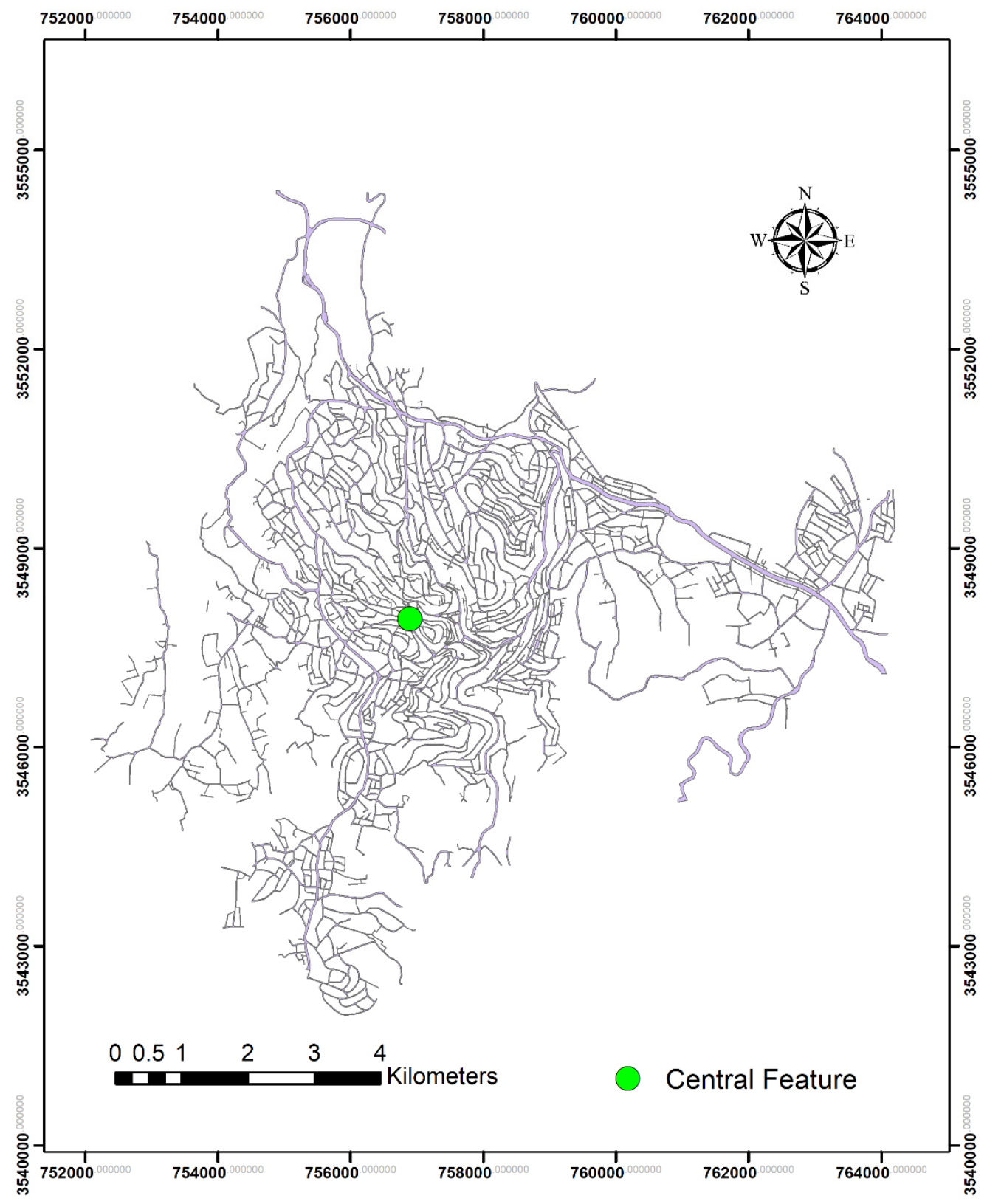

Figure 6. Central Feature in the road of As-Salt City

Figure 6 shows the results of the analysis procedure for the average center of roads, as the standard deviation of roads from the middle position is significant due to the apparent dispersion.

\subsection{Analysis of Standard Distance}

Spatial distributions and scattering or decomposition of geographic features around the middle center are used to calculate the extent to which the distances between the center and geographical features differ from the mean distance, which represents a standard deviation chosen as the radius of the circle. (Shafei, 2008), This is shown in Figure (7). 


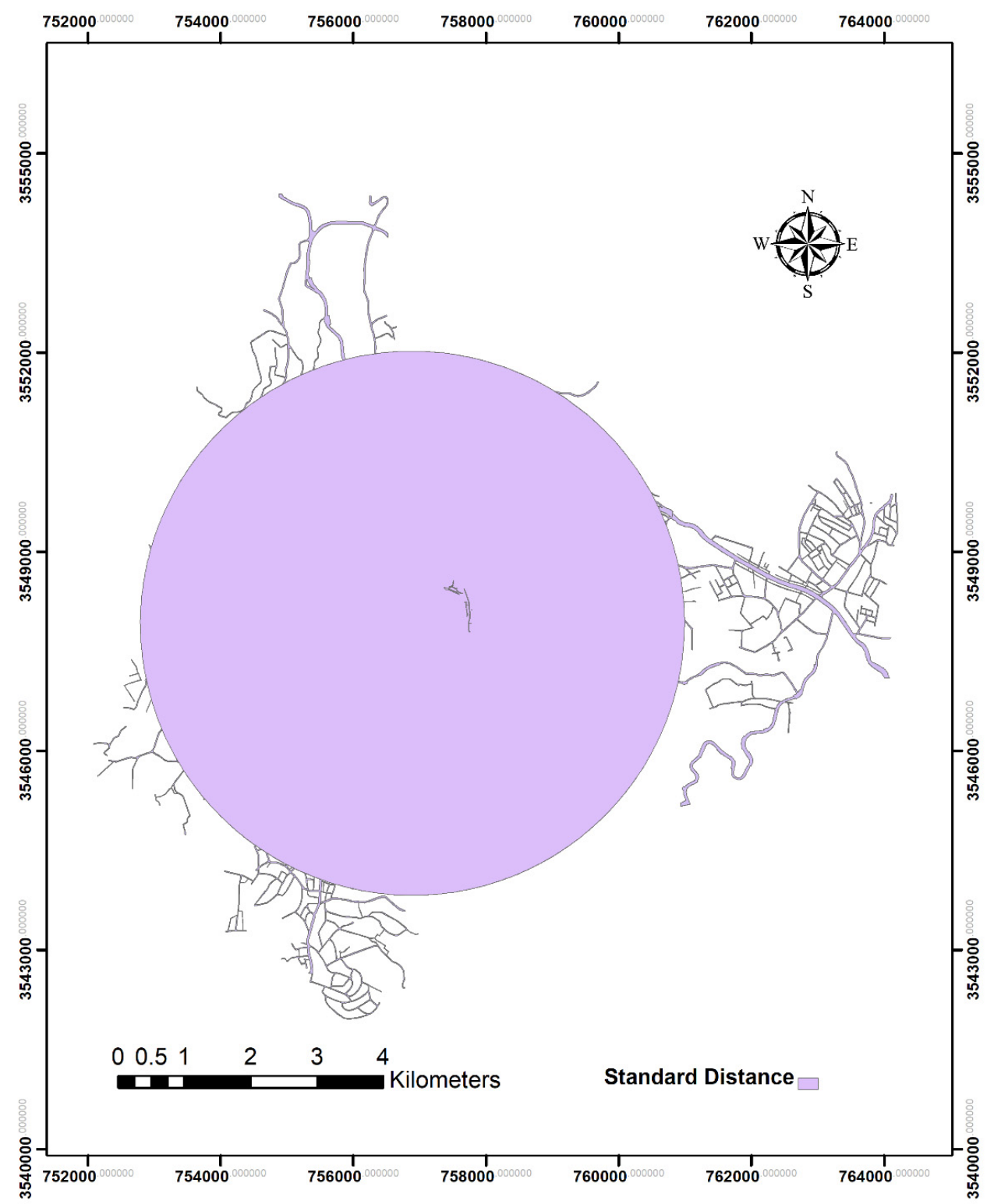

Figure 7. Standard Distance in the road of As-Salt City

The results of the analysis showed the standard distance of the road sites in the study area. The standard distance for each group was $2338.49 \mathrm{~m}$

\section{Conclusion}

The results show that As-Salt City takes irregular shape by analyzing the rate of rotation which is equal to (0.34). The Topographic analysis of As-Salt City explained the presence of steep slope terrains which means that the construction and expansion of road network is difficult, and the elongation ratio analysis classifies the road network in As-Salt City to a rectangular shape because the ratio reaches about (0.95).

The road network is characterized by a high degree of interconnection based on the gamma index with a value of (0.77) while the beta index value is equal to (2.1). The value of the slope index indicates that the study area characterized by a rugged and difficult mountainous terrain, after analyzing the density of the road network the value was $65.5 \mathrm{~km}$ road length serving 10000 people and $16.1 \mathrm{~km}$ road length would contain 1000 vehicle, in the end, $10 \mathrm{~km}^{2}$ of the area contains $1293.5 \mathrm{~km}$ road length.

Future planning for the construction of new roads in As-Salt should be made to reduce traffic jams and facilitate access between nodes or stations. It is recommended to increase the number of roads in the current network to provide new circular roads which increase the efficiency of the road network. There are some roads that need to be re-paved because they are damaged such as Al-Aezareh and Al-Medan Street, GIS programs have to be used 
in spatial planning to determine the optimal use of land and to conduct better selection of routes to achieve good access with minimal costs and efforts.

\section{References}

Abu Madena, H. (2008). Land roads network in Shoa'bat Marzooq. Al Satel magazine, 4, Libya.

Aduory, R. (2010). Geographical Analysis of the Network of Roads in the Duor for 2008. Journal of Tikrit University for the Humanities, University of Tikrit, Iraq, 17(3).

ALjabere,A. (2010). The Use of Spatial Analysis in Evaluating the Spatial Accuracy of Urban Expansion of Kut City. Journal of the College of Education, Wasit, Iraq, 12

Aloush,Q. (2006). Analysis of Transportation Methods and Traffic Conditions in Hilla City, Master Thesis Dissertation - Babylon University - Faculty of Education for Human Sciences. Geography Section, 2(1), Iraq.

AL-nawaeseh, (2016). Analysis of the Structure of the Road Network in Karak Governorate, Southern Jordan. An-Najah University Journal of Research Humanities, 3(80)

AL-masri, A. (2009). Study of the reality of the road network and the movement of passengers by cars in the city of Damascus and its future prospects, University of Damascus, Syria, Unpublished Master Thesis.

Al Tarzy, A. (2003). Paved Roads Network in The Hashemite Kingdome of Jordan and its effect on Cities Growth, Al Yarmouk University. Jordan.

Asdi, A. (2015). Study of Relationship between Roads Network Development and Agricultural Land Conversion in Iran NorthWest. J. Environ, 10(1), 1735-6865https://doi.org/10.1016/j.ccs.2015.12.001

Greater Al Salt Municipality, Geographical information Systems Department, unpublished data. (2016). https://doi.org/10.1016/j.sbspro.2016.06.039

Jeong, Moon \& Han (2016). A typology of network city in a socio-economically disadvantaged region, journal elsevier. City, Culture and Society, 7(2016) 161e168. https://doi.org/10.4314/ejesm.v6i1.9

Rahayu. A. (2015). Land use development and its impact on airport access road. journal ELSEVER, 31-37

Sarkar, D. (2013). Structural Analysis of Existing Road Networks of Cooch Behar District, West Bengal, India, Ethiopian. Journal of Environmental Studies and Management, 6(10). 74-81.

Shabat, A. (2011). The Road Transport Network in Gaza City (study on transport geography using GIS, (M. Sc. dissertation, Islamic University of Gaza). Palestine.

Shehab, A \& Alladin M. (1990). Spatial Requirements for Planning the City, Ministry of Scientific Research and Higher Education, Baghdad.

Siam, w. (1990). Evolution of Transportation in Jordan, National Library, Amman, Jordan.

Taran, A. \& Makhamreh, Z. (2015). Quantitative Analysis of Road Network in the Mafraq Governorate, the Dirasat journal (Humanities and social sciences), University of Jordan, 42.

Todd, L. (2017). Evaluating Transportation Land Use Impacts Considering the Impacts, Benefits and Costs of Different Land Use Development Patterns--Victoria Transport Policy Institute

Tofic (2015). Integrated Co-Evolution Model of Land Use and Traffic Network Design. Netw Spat Econ, 16, 579-603. https://doi.org/10.1007/s11067-015-9289-3

Xie, Y. (2016). Impacts of major vehicular roads on urban landscape and urban growth in an arid. Journal of Arid Environments, 127(2016) 235e244.https://doi.org/10.1016/j.jaridenv.2015.12.002

Xie, Y. \& Weng, Q. (2016). Detecting urban-scale dynamics of electricity consumption at Chinese cities using time-series DMSP-OLS (Defense Meteorological Satellite Program-Operational Linescan System) nighttime light imageries. Energy, 100, 177-189.https://doi.org/10.1016/j.energy.2016.01.058

\section{Copyrights}

Copyright for this article is retained by the author(s), with first publication rights granted to the journal.

This is an open-access article distributed under the terms and conditions of the Creative Commons Attribution license (http://creativecommons.org/licenses/by/4.0/). 